\title{
Foucault and technologies of health
}

\author{
Jason Powell $^{1 *}$ and Sheying Chen ${ }^{2}$ \\ ${ }^{1}$ The Department of Social and Political Science, Westminster Building, The University of Chester, Parkgate Road, Chester, CH1 4BJ, UK \\ ${ }^{2}$ Pace University/Tsinghua University
}

\begin{abstract}
Whilst the earlier work of Foucault has influenced explanatory frameworks for understanding health and medical research, what has not been delineated sufficiently is Foucault's later work of 'technologies of self. This paper unravels some of the conceptual and theoretical insights of Foucault's later work in order to understand ' bio-ethics' as applied to a contemporary understanding of bio-technologies which impinge upon the social re-construction of aging. The paper attempts to show how Foucault's insights allows social scientists to provide both a critical and positive appraisal of aging identity. The paper also reviews the relationship between aging and self-knowing in contexts specific to bio-ethics and bio- technologies of good health management; use of counselling; and bodily enhancement.
\end{abstract}

\section{Introduction}

This article considers how Foucault's concept of 'technologies of self can be related to understanding bio-ethics. We can highlight how a Foucauldian analysis can identify both how the identities of older people are both facilitated and constrained by bio-technologies. The paper reviews major works undertaken my 'critical' theorists of health and medicine such as Armstrong [1] who talks of intense surveillance between subjects and professionals which epitomises Foucault's notion of 'panoptic' power in which surveillance and power relations manifest in a 'top down' or structuralist context. Whilst we have sympathy with such a perspective we also identify the need to employ methodological insights deriving from Foucault's [2] later work in order to provide more of an holistic framework for understanding bio-ethics and old age. In this way we can have an ontologically flexible narrative which illuminates both the constraining and facilitative features of bio-ethics discourses for older people [3].

Nevertheless, a major theme on the health and medical sociological research agenda, the debate about age inequalities in health and access to medicine confronts an essential paradox at the beginning of the twenty-first century. Whilst critical sociological research illuminates enduring socio-economic differentials in the life course $[4,5]$ and the importance and significance of biography, time and longitudinal life course research [6]- the central issue remains that once a standard of living and epidemiological foundation has been established, other, more dispersed and intangible factors take over as major determinants of 'socially patterned' disease in the global arena. Central to these developments has been a growing interest in 'bio-ethics' and use of technologies of bio-medicine. There are a number of value dilemmas in the care and medical treatment for older people that relate to ethical decision-making [7]. However, it is how decisions are made and who makes decisions, which impinge upon access to health care and issues of inclusion and exclusion.

Moody [7] claims a crucial ethical debate in health and medicine is whether older people should have their health care needs and resources curtailed simply because of their 'age'. Such an ethical statement and stance justifies ageism via the exclusionary processes of a social grouping based upon their chronological 'age'. Before, we rethink bio-ethics we need to understand current thinking on bio-ethics. In common-sense usage, the concept of 'bio-ethics' is full of disparate associations. It is a esoteric word, and in everyday conversation between non-specialist, and informed participants, few would claim to know exactly what it means. And yet the word is often used, as if its meaning were obvious and understood by all.

Other connotations of bio-ethics are more broader in outlook: here 'bio-ethics' points to a more comprehensive medical and postmodern outlook capable of addressing psychological, biological and cultural dimensions of health and disease [8]. Significantly, bio-ethical dimensions of older people's experiences relate to two distinctive narratives: 'holistic' and 'alternative'. A holistic approach to cancer suggests special attention be paid to the older 'patient' as a whole. An alternative approach suggests non-invasive diagnostic and therapeutic procedures, techniques and bio-technologies of health management and cure for older people [9].

Ambivalence can be seen in the tension between manifest justifications of health technology and the parallel attitudes and relational inequalities that accompany it. Intervention is justified as helping behaviour; a remedy to personal distress and it's potential for increased quality of life. However, the application of bio-technology can also perpetuate a part-view of people as 'bodies with illnesses or dysfunction's that reduces legitimate experience to passive feedback on technological success. If we move into the terrain of the sociology of health we find a similar ambivalence. Sociology proposes to analyse the 'bio-social' aspects of the aetiology of health and illness $[1,9]$. A significant contribution of sociology as a discipline has been to highlight how individual lives and illnesses which was thought to be determined solely by biological, medical and psychological factors, are, in fact, heavily influenced by social environments in which people live. This remains invisible to the bio-medical approach because they

Correspondence to: Jason Powell, PhD, FHEA, FRSA, FRSPH, The Department of Social and Political Science, Westminster Building, The University of Chester, Parkgate Road, Chester, CH1 4BJ, UK, E-mail: j.powell@chester.ac.uk

Received: October 24, 2017; Accepted: November 09, 2017; Published: November 13, 2017 
stem from the social interaction before becoming embedded and recognisable as illness in the aging body of the patient. For example, in the 'sociology of emotions' the excursion of inquiry has proposed that 'stress' is not only rooted in individualistic emotional responses but also regulated, classified, and shaped by social norms of western culture [10]. This type of research enables the scope of health and illness, and the medical outlook, to be broadened beyond traditional individualistic accounts of the body. On this basis alone, sociology has invited us to recognise the disease of the older patient is not only his or her own problem but rather the symptomatic deep manifestation of underlying relations of power and inequality [11]. At this structural tier of analysis, sociology addresses medicine as one of the elements of social control and domination legitimated through knowledge and power of 'experts' [11-14]. This in part explains the reluctance of medical discourses to adopt perspectives that would radically undermine this role [9].

\section{Biomedicine, sociology and the contestation of 'truth'}

Drawing from the earlier work of Foucault, David Armstrong $[1,15]$ has warned sociological disciplines against the seduction of a relationship of co-operation whose terms remain dictated by medicine itself. He further cautions sociological disciplines against becoming 'an emasculated, uncritical appendage' of biomedicine, as a result of endorsing too easily an alliance of bio-social perspectives. This proposal, Armstrong contends, should be regarded as a veil offered in response to increasing consumer dissatisfaction with medicine's failure to address patients as persons. Similarly, a number of Foucauldian gerontological arguments have developed in recent years that claim medical power must be regarded as a 'dangerous' expansion of power and surveillance which reaches into the lives of older people $[11,14,16,17]$. Nevertheless, perhaps a reflective criticism of Armstrong's warnings is that the difference between biomedicine and sociology is illusory as both comply with the aging body-as-object as the main criteria of pathological 'truth'. In this discursive context, the connotation of 'bio-ethics' raises critical questions about how twothirds of deaths in the USA occur amongst older people [7]. Access to health care services is contingent across and through the blurred structural fault lines of 'race', class, gender, sexuality, disability and how these inter-relate with age but also through the negotiative power of institutional and professional practices who provide medical and health care for older people. Can we rethink this? Henceforth, bioethics requires explanation, rectification and re-appropriation. The sociological alternative is a challenge to what is seen as a form of 'epistemological imperialism' in the definition of bio-ethics [18]. Thus, the sociological tradition juxtaposes social understandings of disease to the biological definitions that are operant in medical institutions.

Bio-ethics conveys associations of deception and self-deception; or it conveys that older people have failed to 'get oneself together' in managing health situations [7]. Indeed, there is the suggestion that we as human beings are 'responsible' [19] for looking after our own health needs. The important point Nikolas Rose is making is that the problem of illness bears on the constitution of the self as an ethical subject, the sense of what we do with our freedom, the extent to which we acknowledge it and with it, and the extent to which we engage with attributions of self responsibility. As Arney and Bergen [20] suggest, an interpretation of modern medical encounters should start:

'not in the doctors office but in the modern bookstore.... Indeed the modern bookstore suggests that patients, ex-patients and would be patients are forming themselves into a social movement that is not unlike a rebellion. It seems the self is asserting itself against medical indifference to the experiences and emotions that make up life, and it seems that the self is calling into question the power of the physician'.

The increasing popularisation of some key terms of biomedicine has had the effect of producing an intra-subjective consciousness, and a conspicousness of behaviour, either for health or against it. Moral action, whether it is individual or collective, involves the selfknowing the self, a process of self-formation as an ethical aging subject. Self-responsibility, when passed through the metaphor of 'health', becomes a covert form of moral judgement upon which decisions to supply or deny (often-expensive) forms of bio-technology can be made. A 'healthy old age' no longer represents good fortune, but is seen to be the result of prudent self-care currently, and in the past. A healthy old age signifies that one has lived a 'moral life' that not only has its own rewards, but relieves others of any obligation, financial or otherwise, to care. By comparison, becoming unhealthy approximates being undeserving. One is unwell because one is unhealthy and one is unhealthy because the proper steps of self-care had not been taken in the past. So why should others have to provide scarce resources to make good this moral turpitude? Such an attitude to the healthy body presents moral decisions on the supply and demand for services in the 'neutral' language of techno-medical science. However, the outcome is that the prudent do not need it whilst the imprudent do not deserve it. Any allusion here to economic planning and to pension policy is more than passing for in both cases it is the resource-rich who can afford, but may rarely need such technology, whereas the resource-poor are denied it. But under such conditions, Foucault [21] claims ethical practices involves individual subjectivity to analyse themselves and their own 'needs' as it involves:

'a process by which the individual delimits that part of himself that will form the object of his ethical practice, defines his position relative to the precept he will follow, and decides on a certain mode of being that will serve as his moral goal. And this requires him to act upon himself, to monitor, test, improve and transform himself.

Despite a huge upsurge in the label of 'Foucauldian' attached to medical sociological research, this has tended to draw upon Foucault's $[12,22,23]$ earlier work $[1,15]$. Whilst there is a small but growing body of gerontological knowledge which draws from Foucault's [2] later work in Canada and USA [24] in examining 'technologies of self, this remains quite invisible in the critical gerontological literature in the United Kingdom despite some exceptions [19]. The rest of the paper seeks to understand and inter-connect the theoretical perspective of 'technologies of self and relate to old age and aging that is relevant to the discourses and practices of bio-ethics.

\section{Foucault, Technologies of Self and Aging}

'It may be that the problem about the self does not have to do with discovering what it is, but maybe has to do with discovering that the self is nothing more than a correlate of technology built into our history' [25].

Foucault's formulation presumes the notion that individual lives are never quite complete and finished - that in order to function socially individuals must somehow work on themselves toturn themselves into subjects. The notion of 'technologies' offers the opportunity for a particular analysis of the sites and methods whereby certain effects on the subject are brought about. Objectifying technologies of control are for example those invented in conformity with the facets of selfunderstanding provided by criminality, sexuality, medicine and psychiatry investigated by Foucault. These are deployed within concrete institutional settings whose architecture testifies to the 'truth' of the objects they contain. For example, the possibilities of self-experience on 
the part of the subject are in itself affected by the presence of someone who has the authority to decide that they are 'truly' ill such as a 'doctor' of medicine [1]. 'Subjectifying' technologies of self-control are those through which individuals: 'effect by their own means or with the help of others a certain number of operations on their own bodies and souls, thoughts, conduct and way of being, so as to transform themselves in order to attain a certain state of happiness, purity, wisdom, perfection or immortality' [2].

These important issues are associated to 'truthful' formulations of the task or the problem that certain domains of experience and activity pose, in this case for older people themselves. The boundaries of self-experience change with every acquisition, on the part of older individuals, of a possibility, or a right, or an obligation, to state a certain 'truth' about themselves. For example, bio-technology can tell a 'truth' of selling a dream of unspoken desire of 'not growing old' to older people. However, it is the self-experience of aging subjects that can refute, deny and accept the 'truth' claims of bio-technology. In the case of aging lifestyles, the active adoption of particular consumer practices, such as uses of bio-technology contributes to a narrative that is both compensatory and 'ageless' in its construction of self. Thus, the recourse to the notion of technologies of self is capable of accommodating the complexity of the 'subject'. Although Foucault maintained the distinction between the technologies of power/domination and the technologies of self, these should not be regarded as acting in opposition to or in isolation to one another. Indeed, Foucault frequently spoke of the importance of considering the contingence of both in their interaction and interdependence, by identifying specific examples 'the point where the technologies of domination of individuals over one another have recourse to processes by which the individual acts upon himself and, conversely, the points where the technologies of the self are integrated into structures of coercion' [25]. The distinction should therefore be considered as a heuristic device and not the portrayal of two conflicting sets of interests. Indeed, it is mythical to suggest that Foucaults early and late works are apposite: they are complementary in understanding social relations.

If we relate Foucault's main aims mapped out to the 'aging body' and disease - all disease that pertains to the aging body in its concrete objectivity is beyond the foundation of relevance as the expression of a subjectivity evidences a relation between the ethical subject and truth. That is what changes, what is newly problematized, in modern bio-ethical discourse. How then is modern bio-ethics rooted in a specific configuration of subjectivity? The task of the rest of the paper is to highlight some of the conditions of how bio-ethics as a form of problematization, poses as a question of illness treatment and bodily enhancement. The aging body culturally represents the best hiding place, a hiding place of internal illnesses that remains inconspicuous until the advent of bio-ethics. We can also probe how this problematic modifies the possibilities for the constitution and transformation of the self as a subject. In other words, what are the effects of this problematization given its conditions of possibility? Subjective relations to the self will be affected to the extent that bio-ethics confronts older people with the proposition that this subjective truth - the truth of their relation to themselves and to others - may be revealed by their 'aging bodies'. If this is legitimate, we may anticipate through 'biology and culture' [8] the problematic of illnesses associated with aging rejoins the sphere of bio-ethics, in modernity, through the back door. 'Illness' as problematized by bio-ethics will again belong to the strategic margin that older people embodies as subjects of purposeful action. While confronting an illness this involves a deliberate practice of selftransformation and such tranformativity must pass through learning about the self from the truth told by narratives of illness [24,26]. This is what we can glean as a hypothesis, by building abstractly on contemporary arguments that chart the development of a privileged relationship between the aging self and its truth. The rest of the paper examines whether and how different aspects of these conditions of possibility organise the actual propositions of bio-ethical discourse. The paper analyses in particular how technologies of the self can be applied to three specific areas of aging: maintenance of health; increase in counselling; and bodily enhancement.

\section{Aging and illness}

With the rise of modernity, the 'hospital' became a specialised therapeutic place and supporting structure for the medical staffing of the elderly population as 'patients' [16]. The rise of western rationality made it possible to medicalise hospitals: this is how the production of medical knowledge was spatio-temporally aligned with the medical treatment of many elderly patients. The relevance of this institutional process to the development of bio-ethics can be appreciated via a detour through classificatory practices [3]. Within the analytical economy of assistance, the notions of the 'sick' and the 'ill' patient have appeared as newly distinctive modern categories [16]. The new knowledge spoke of forms of pathology relating to the capacity to will, to act, to make decisions and ultimately to be free to choose medicines to meet ill needs. The development in the U.K of a universal National Health Service (NHS) seemed to reiterate and sanction this knowledge problematic. Universal access to medical and health care was a key discursive touchstone of the state's reconstruction of society after world war two [4]. However, older people were portrayed as a stoical and heroic survivor in the immediate post-war period in Britain, this image was contingent upon an absence of demand upon the rest of society. This ambivalence was reinforced by the difficulty of reconciling old age with the rhetoric of progress and investment for the future that characterised the growth and ideological justification of childcare. Neither did older people fit narratives of production, work and usefulness to capitalist production. Old age then took on a problem focus. These narratives held dominant ideas that helped shape and legitimise policies of retirement and subsequent inequality. Indeed, 'old age' throughout the twentieth century has been seen as a social and medical problem and this predominant perspective is evident through the language used by policy makers. Similarly, at the turn of the new millennium, access to health care has become fragmented and limited, contingent upon regional variations of 'waiting lists' and medical priorities. Such a fragmentation of access to health care impacts upon unequal social relations between social groupings across the lifecourse and subsequent claims for access to health care.

The shift from universalism to fragmentation has had the effect of creating a 'consumer culture' which is symptomatic of postmodernity $[27,28]$. Within a Postmodern analysis, we can deconstruct biological classifications of old age and instead reconstruct the cultural implications of population aging. Blaikie looks to the increased leisure opportunities associated with old age and claims consumer culture is breaking down dominant rigid stereotypes of marginalisation and medicalisation. Within such a state of condition, Blaikie [29] claims there are spaces for self-regulation which allow for better understanding of ourselves and our health needs. Similarly, the paper appropriates the usefulness of 'technologies of self as applied to more healthy aging practices. Indeed, technologies for the healthy aging self can be identified in at least three areas: first, there is the growing interest in the maintenance of existing good health [30]. This would include the growing market for healthy eating and exercise from midlife onwards; second, there is an 
increase in the use of counselling, and most notably narrative therapies in later life [14,31]; third, there is the use of 'bio' and other forms of technology to modify and in some cases enhance bodily [27,32]. These technologies of self very much epitomise the earlier discourse derived from Nettleton [9] as alternative therapeutic procedures, techniques and bio-technologies of health management and cure for older people.

In the first case, it has been noted [33] that whereas in previous eras, the control of the body had been enhanced by external constraining virtue of the corset, contemporary shaping has involved active working, through exercise and diet. The multiplication of magazine articles, selfhelp manuals, diet and exercise clubs, extending through midlife and beyond also bear witness to the popularity of attempts to work on the self in this way. Baltes and Carstenson [30] have indicated that a closer attention to the maintenance of bodily and mental capacity is typical of later life.

The use of diet and exercise as techniques specifically related to later adulthood, is closely related to the growth of leisure and a lifestyle approach to the creation of late life identities. It therefore resonates beyond the simple fuelling and repair of the bodily machine to include a continual re-creation of the self within a particular social discourse. This discourse closely associates the construction of a healthy lifestyle with positive self-identity [3].

Perhaps the most notable increase in the use of technologies of the self can be seen in the use and promotion of counselling and psychotherapy for older adults. Having for many years been actively discouraged, lifecourse counselling, and most notably narrative counselling is currently undergoing a gerontological renaissance $[14,31]$. The focus here has been on 're-storying' or re-inventing oneself in line with current life-priorities. It involves a characteristically different relationship to the personal past than that adopted by traditional psychotherapy. Whereas the past had previously been seen as a repository of experiences that determined choices in the present, the narrative approach sees personal memory as a sort of 'rag-bag' of vignettes and experiences that can be recombined to tell whatever story best fits contemporary identity needs. McAdams [34], perhaps the best known narrative therapist and one with a particular interest in midlife identity, links the popularity of narrative techniques with wider social trends toward a blurred lifecourse. 'Because' he states 'our world can no longer tell us who we are and how we should live, we must figure it out on our own' [34]. This technology and discourse has been invented which promotes self-care. This time the focus is on the psyche: a healthy mind is associated with the capacity to re-author oneself and keep that narrative going.

The third example of a technique of self refers to a direct use of new technology to either modify the appearance or performance of identity. To paraphrase Morris [8] technologies here hold out the promise of 'utopian bodies'. Indeed, Haraway's [35] original reference to cyborgic fusion of biological and machine entities has been enthusiastically taken up by postmodern gerontology. The list of technologies available extends beyond traditional prosthesis to include virtual identities created by and reflected in the growing number of 'silver surfers' using the Internet as a free-floating form of identity management. Thus Featherstone and Wernick [28] trill that it is now possible to' Re-code the body itself 'as biomedical and information technologies make available' the capacity to alter not just the meaning, but the very material infrastructure of the body. Bodies can be re-shaped, remade, fused with machines, empowered through technological devices and extensions'.
In each case, a technology has been employed in order to re-shape the aging self in later life, in order to overcome or destabilise existing discourses on the aging self. The ethics of such re-invention have been explored in terms of the economic costs and personal benefits that might accrue, and have been outlined at the beginning of this paper.

\section{Conclusion}

Whilst some sociological input has been influenced by the earlier of work of Foucault in raising critical questions of the medical 'gaze' of aging [3] this paper has sought to complement such an approach through how subjectivity can be delineated as a core concept in understanding aging and bio-ethics. Indeed, the discourse of bioethics shifts the question of health from an ontology of disease dominated by professional discourses $[1,15]$ to an elaborate analysis of 'technologies of self [2] and how this analytical metaphor bears reality on some social practices of bio-technology which impinges upon a social reconstruction of the ethical aging subject. Through the use of a Foucauldian narrative, we have explored three areas of: the maintenance of good health; use of counselling narratives; and bodily enhancement. These three technologies have been used to illuminate the different ways in which the aging self has been re-shaped and will continually be re-shaped by the self's own consciousness (technologies of self) and by others (technologies forself).

\section{References}

1. Armstron D (1983) The Political Anatomy of the Body. Cambridge: CUP.

2. Foucault M (1988) Technologies of the Self. In: Martin, L.H et al. (Eds.) Technologies of the Self, London: Tavistock.

3. Powell J (2005) Social Theory and Aging. Rowman and Littlefield: NY

4. Alcock P (1996) Social Policy in Britain: Themes and Issues. London: Macmillan.

5. Walker A (1990) 'Poverty and Inequality in Old Age' in Bond, J and Coleman, P (Eds.) Ageing in Society: An Introduction to Social Gerontology, London: Sage.

6. Wadsworth ME (1997) Health Inequalities in the Lifecourse Perspective. Soc Sci Med 44: 859-70. [Crossref]

7. Moody H (1998) Aging, Concepts and Controversies. Thousand Oaks: Pie Forge Press, Sage.

8. Morris DB (1998) Illness and Culture in the Postmodern Age. London: University of California Press.

9. Nettleton S (1995) The Sociology of Health and Illness. Cambridge: Polity Press.

10. Freund P (1988) Bringing society into the body: understanding socialized human nature. Theory and Society 17: 839-64.

11. Powell J, Biggs S (2000) Managing Old Age: The Disciplinary Web of Power, Surveillance and Normalisation. Journal of Aging and Identity 5: 3-13.

12. Foucault M (1972) The Archaeology of Knowledge. London: Tavistock.

13. Foucault M (1982) 'The subject of Power' in Dreyfus, H and Rabinow, P (Eds.) Michel Foucault: beyond structuralism and hermeneutics. Brighton: Harvester.

14. Biggs S (1999) The Mature Imagination. Buckingham: OUP.

15. Armstrong D (1987) Theoretical tensions in biopsychosocial medicine. Soc Sci Med 25: 1213-1218. [Crossref]

16. Katz S (1996) Disciplining Old Age: The formation of gerontological knowledge. Charlottesville: University of Virginia.

17. Powell J (1998) The Us and The 'Them': Connecting Foucauldian and Political Economy insights into ageing bodies. British Sociological Association Annual Conference, University of Edinburgh.

18. Strong PM (1979) Sociological imperialism and the profession of medicine. Soc Sci Med 13: 199-215. [Crossref]

19. Rose N (1990) Governing the Soul: The Shaping of the Private Self. London: Routledge. 
20. Arney W, Bergen B (1984) Medicine and the Management of Living. Chicago, IL: University of Chicago Press.

21. Foucault M (1987) Mental Illness and Psychology. Berkely, CA: University of California Press.

22. Foucault M (1967) Madness and Civilisation. London: Tavistock.

23. Foucault M (1977) Discipline and Punish. London: Tavistock.

24. Frank AW (1998) Stories of illness as care of the self: a Foucauldian Dialogue. Health 2: $329-348$.

25. Foucault M (1993) About the beginning of the hermeneutics of the self. Political Theory 21: 198-227.

26. Frank AW (1996) The Wounded Storyteller: Body, Illness and Ethics. Chicago: University of Chicago Press.

27. Featherstone M, Wernick A (1995) Images of Ageing. London: Routledge.
28. Carter J (Ed.) (1998) Postmodernity and the Fragmentation of Welfare. London: Routledge.

29. Blaikie A (1999) Ageing and Popular Culture. Cambridge: Cambridge University Press

30. Baltes M, Carstensen L (1996) The Process of Successful Ageing. Ageing and Society 16: $397-422$.

31. Knight B (1996) Psychodynamic therapy with Older Adults. In Woods, R (Ed.) Handbook of the Clinical Psychology of Ageing, Chichester: Wiley.

32. Shilling C (1993) The Body \& Social Theory. London: Sage.

33. Gittens C (1997) The Persuit of Beauty. London, NPG.

34. McAdams D (1993) The Stories We Live By. New York: Morrow.

35. Haraway D (1991) Simians, Cyborgs and Women. London: Free Association Books.

Copyright: @2017 Powell J. This is an open-access article distributed under the terms of the Creative Commons Attribution License, which permits unrestricted use, distribution, and reproduction in any medium, provided the original author and source are credited. 